\title{
SOBRE POLITICAS DO CORPO NEGRO FEMININO E TERRITORIALIDADES JONGUEIRAS NO ENFRENTAMENTO AO RACISMO
}

\author{
ON POLITICS OF THE FEMALE BLACKBODY AND JONGO'S \\ TERRITORIALITIES IN THE FIGHTAGAINST RACISM
}

Patrícia Gomes Rufino Andrade

DEPS-UFES

\begin{abstract}
Resumo: $O$ presente texto destaca reflexões sobre políticas do corpo negro instituídas por mulheres jongueiras a partir de aproximações nas práticas culturais do Sapê do Norte. Busca desconstruir a representação estereotipada de subalternidade da mulher negra, enfatizando como as comunidades percebiam historicamente os processos de opressão racial e em contraponto criavam estratégias para fortalecer a liderança feminina. As questões de interseccionalidade de gênero são discutidas sob esse prisma, constituindo territorialidades e contextos de autoafirmação. Nas rodas de jongos o corpo é premissa da relação ancestral, da circularidade expressa nos ciclos geracionais interligando o passado e o presente por meio dos cantos e danças. É neste contexto que traçamos alguns paralelos sobre territorialidades femininas, ancestralidade, circularidade.
\end{abstract}

Palavras-chave: Jongos, territorialidades femininas, ancestralidade, circularidade.

\begin{abstract}
This text highlights reflections on black body policies instituted by Jongueira women based on approximations in the cultural practices of Sapê do Norte. It seeks to deconstruct the stereotyped representation of blackwomen's subordination, emphasizing how communities have historically perceived processes of racial oppression and, in contrast, created strategies to strengthen female leadership. Issues of gender intersectionality are discussed from this perspective, constituting territorialities and contexts of self-assertion. In jongo circles, the body is the premise of the ancestral relationship, of the circularity expressed in the generational cycles that link the past and the present through songs and dances. It is in this context that we draw some parallels about territorialities, ancestors, female circularities.
\end{abstract}

keywords: Jongos, female territorialities, ancestry, circularity. 
Das muitas formas de se pensar o enfrentamento ao racismo de gênero, penso que discutir como as práticas culturais cooperam para esse enfrentamento seja uma delas. Assim, resolvi partilhar neste texto alguns aprendizados deste caminho de estudos e pesquisas junto de comunidades negras, dialogando sobre suas histórias. Um percurso nada fácil. Inicialmente porque dentre as multiplicidades de perspectivas sobre as quais trabalhamos relações étnico-raciais, quando chegamos às comunidades percebemos o quanto temos a aprender, no entanto, é necessário compreender como práticas culturais se constituem em processos instituintes e se traduzem em práticas antirracistas. Este aprendizado só é possível com proximidade, junto das comunidades, porque são elas que trazem a carga ancestral deste reconhecimento, são elas que nos dizem como fazer.

Neste texto buscarei agregar um pouco da relação mística ancestral na concepção do feminino, e por outro lado, apresentar estratégias de enfrentamento a partir da forma como se constituem histórica e socialmente nos grupos de jongos ${ }^{1}$. Penso ser este mais um ponto para pensarmos sobre os contextos de autoafirmação das mulheres negras quilombolas, no exercício das práticas culturais.

Jongos e caxambus interligam percepções da arte às geografias do corpo, produzindo territo-

1 Este texto faz parte de pesquisas realizadas durante o Programa "Jongos e Caxambus: memórias de mestres e patrimônio cultural afro-brasileiro no ES” tem caráter interdisciplinar envolvendo as áreas de Artes, Antropologia e Educação, tanto no que se refere às ações de extensão, quanto ao ensino e às pesquisas de graduação e de pós-graduação; promovendo parcerias entre diferentes Departamentos (DTAM/DCSO/DEPS), Centros (CAR/CCHN/CE) e PPGs como o Mestrado em Artes (PPGA), em Ciências Sociais (PGCS) e em Educação Profissional (PPGMPE) da UFES. O Programa é coordenado pela professora Aissa Afonso Guimarães em parceria com os professores Osvaldo Martins de Oliveira e Patrícia Gomes Rufino Andrade. rialidades. Por territorialidades entendemos as diversas estratégias de grupos sociais para criar, manter ou transformar o espaço vivido (HAESBART,2007; SACK,1986). Para além das viviências e curiosidades das ancestralidades jongueiras, identificamos experiências que nos remetem a africanidades conservadas nas diáporas africanas no Brasil, perpassadas de geração em geração como processos de vida, resistência.

Nos jongos, a construção política do corpo negro feminino advém dessas heranças ancestrais que conjugam a materialidade do comando, da liderança às heranças ancestrais africanas, recriadas nas senzalas, sobre o prisma das diferentes etnias desterritorializadas (HAESBART,2007). Esse processo compreende a resistência territorial, corporal, sagrada - território físico; do corpo; religioso.

Os enfrentamentos à opressão pelas comunidades negras na contemporaneidade, constituem a ruptura do estereótipo objetificável do corpo da mulher escravizada, que ao longo da história foi produzido pelo olhar do colonizador, idealizada como serviçal, subalternizada, para pensar um outro ciclo social constituído no seio das comunidades negras: a mulher geradora, protagonista, autorreferenciada. Tornar-se negra entendendo este processo, passa pela aprendizagem do reconhecimento desta mulher com seu próprio corpo, com sua comunidade e de religação com sua ancestralidade. 0 jongo preserva essa relação direta com a condição ancestral, constituindo-se forma do prórpio corpo abrir-se, expandir-se, falar de si.

No livro "Memórias da Plantação", Grada Kilomba (2020) se refere aos processos de silenciamento por quais passavam os escravizados, com uma máscara de ferro ateada em suas bocas e tantas outras formas de silenciamento do corpo. A visão colonial do controle sobre o corpo, a voz, o sexo foram aos poucos assimila- 
dos pelos escravizados, constituindo uma perspectiva intrínseca aos processos de racialidade e enfrentamento, mas também de subjulgação. Sob outro prisma, a compreensão destas orpressões constituiram-se em estratégias de oposição e fortalecimento de lideranças femininas que, historicamente no enfrentamento destas forças, evidenciaram aprendizagens intergeracionais, passadas dos mais velhos aos mais novos como estratégias de sobrevivência.

As comunidades jongueiras sempre tem um santo padroeiro de consagração: São Benedito, Santo Antônio, São Bartholomeu, Sant'Anna. É comum as meninas acompanharem suas mães e avós nas devoções. Esse apecto pressupõe a relação interseccional, atuando no contexto da afirmação de gênero, geracional, racial e da construção da liderança. As devoções são o encontro com o sagrado. Momento em que as comunidades se agregam para fazerem suas orações, lembrarem dos mais velhos, e de como as rezas, recriam memórias, fortalecem a fé. Também são encontros de gerações, porque ressignificam os contextos de mães, tias, avós, em que as mais velhas se fazem presentes repassando o que aprenderam, mesmo que, diante de tal feito, as moças das novas gerações, ainda não compreendam a amplitude deste ato.

Neste sentido, a maestria das mulheres jongueiras está em instituir esse aprendizado da resistência, das estratégias para denúncia das opressões e dos sentidos para empoderamento do corpo feminino. O próprio ofício de mestras, compreende as narrativas geracionais de liderança a que me refiro, pois para chegarem a tal feito, é necessário, empostar-se do histórico familiar, da guarda dos tambores sagrados, da responsabilidade de levar os jongos e caxambus como ofício e devoção, também sobrepõem o cuidado comunitário. Portanto, o "oficio" de mestra, vem carregado de história, de poder, de ancestralidade.
Paralelamente a todo esse processo de formação as mestras apresentam suas histórias, trazem seus medos e anseios conjugando-os entre um universo místico, mágico a visão multifacetada das práticas afrocentradas, da circularidade das rodas, das memórias dos mais velhos e de como essas práticas vão constituindo-se em territorialidades femininas religando africanidades e sagrado. Parte do que descreveremos aqui foi extraído de perspectivas conflitivas em rodas de conversa, observando as mestras em seus ofícios em campo, e parte foram vivenciadas nas apresentações de jongos, nas oficinas formativas, em entrevistas coletadas durante os encontros.

Remontando a estrutura filosófica de mundo, pela cosmovisão africana, podemos entender a circularidade como princípio fundante de vida, ou seja, nossos contextos, convívios e possibilidades organizam- se em ciclos. O complexo pensamento da circularidade contribui para refletirmos sobre a ruptura das relações de dualidade- homem/mundo, homem/terra, homem/ espiritualidade, feio/bonito, homem/mulher, sagrado/profano, bem/mal.

Um dos percursos desse pensamento complexo, busca na circularidade entre a análise (a disjunção) e a síntese (a religação), ultrapassar o reducionismo e o "holismo" e reconhece a circularidade entre as partes e o todo (Morin, 2002). Nesse sentido, a circularidade diz respeito, igualmente, ao caráter do pensamento cíclico, mítico, muitas vezes relacionado à sociedades tradicionais em que os tempos passados, presentes e futuros se processam paralelamente. Assim observamos que os elementos do passado podem voltar ao presente especialmente através da memória.

Outra relação importante é que o círculo nos alerta em relação a fragmentação. Possibilita refletirmos a fragilidade profunda e grave da 
fragmentação dos saberes, dos organismos, dos seres, das disciplinas, do outro, dos gêneros, por outro lado, nos incita a repensar a multiplicidade, transversalidades, globalidades.

Os conflitos existentes no trato das questões raciais na Educação Brasileira, devem-se a letalidade na formação, e logicamente ao racismo estrutural, que influencia diretamente as instituições. É preciso levar em consideração que o racismo é fruto de um projeto de nação, portanto, necessário considerar que nossa formação é e continua sendo altamente racista. Essa compreensão deve-se não só pelas performances adotadas pela escola, no processo de educação formal - evidenciamos principalmente na ênfase sobre as datas comemorativas - mas sobretudo, na falta de compreensão processual sobre a racionalidade estética das africanidades brasileiras. Nessa perspectiva, a proposição é trabalhar o antirracismo, compreendendo que educar para relações étnico-raciais refere-se a africanidades também na escola.

Conforme a professora Petronilha Beatriz Gonçalves e Silva (2007), o conceito de africanidades brasileiras, no que diz respeito ao processo ensino-aprendizagem, conduz a uma pedagogia antirracista, cujos princípios são: respeito, entendido não como mera tolerância, mas como diálogo em que seres humanos diferentes se miram uns nos outros, sem sentimentos de superioridade ou de inferioridade; levam também à reconstrução do discurso pedagógico, no sentido de que a escola venha a participar do processo de resistência dos grupos e classes postos à margem, bem como contribuir para a afirmação da sua identidade e cidadania. Refere-se também ao estudo da recriação das diferentes raízes da cultura brasileira que, nos encontros e desencontros de umas com as outras, se fizeram e hoje não são mais Gegê, nagô, bantu, portuguesa, japonesa, italiana, alemã, mas brasileira de origem africana, europeia, asiática. As africanidades brasileiras abrangem diferentes aspectos. Não precisam, por isso, constituir-se numa única área, pois podem estar presentes em conteúdos e metodologias, nos diferentes campos de conhecimento constitutivos do currículo escolar.

Ainda sobre esse prisma, é necessário mencionar que faz parte da educação brasileira a reconstrução histórica dessas africanidades. Muito embora a Lei n. 10.639/03 altere a Lei de Diretrizes e Base da Educação Nacional, estabeleça a obrigatoriedade do ensino de História e Cultura Afro-Brasileira e Africana na educação básica pública e privada em todo o país há um processo incipiente de rejeição à proposta, muitas vezes pelo desconhecimento do que essa lei signifique. Essa rejeição atinge justamente a racionalidade estética de que falamos anteriormente. O aguçar histórico sobre o reconhecimento dos povos africanos e suas cosmovisões, deveriam desde sempre fazer parte dos processos educativos escolares, não fosse, a visão colonizadora de hierarquia racial enfatizada pelas relações de poder. A lei tornou-se um instrumento crucial para as discussões no campo da educação em comunidades quilombolas, sobre a concepção do que seriam essas práticas culturais e de reconhecimento fundamental para compreensão dos ajuntamentos comunitários. De fato, a lei constituiu-se como fomento para a formação de professores na temática, principalmente para o enfrentamento ao racismo nas instituições. Dessa maneira, juntamo-nos aos muitos jongueiros, educadores, pesquisadores, militantes que, de alguma forma, contribuem/ contribuíram para a redução do racismo em nosso país, o projeto jongos também teve essa perspectiva.

Neste texto, as narrativas das mestras são frutos de um percurso de alguns anos em campo 
- (2005 -2018) pesquisa de mestrado, doutorado e especificamente acompanhando o Projeto de Extensão Jongos e Caxambus no Espírito Santo ${ }^{2}$. A Geografia dos corpos, dos ritmos e de gênero, é trabalhada aqui na perspectiva da construção dos espaços sociais e das transformações culturais existentes nos territórios, identificando relações entre aqueles que o modificam e suas expectativas relativas ao reconhecimento político, já que, em se tratando de comunidades quilombolas rurais, permanecem as questões da terra e seus desdobramentos relativos ao autorreconhecimento e aos direitos conquistados.

\section{Processos insurgentes das práticas jongueiras}

Chamado de jongo em alguns lugares e caxambu ${ }^{3}$ em outros, a distinção entre ambos é apresentada por mim na tese "Sobre olhares entre jongos e caxambus - projetos educativos nas prpáticas culturais afro-brasileiras ${ }^{4 " \prime}$ são

2 Todas as entrevistas, narrativas e informações fazem parte do Banco de Dados do Programa de Extensão Jongos e Caxambus - Culturas afro-brasileiras no Espírito Santo (PROEXT 2012/2013 - Cf. SigProj), coordenado pelo professor Osvaldo Martins de Oliveira (PPGCS/DCSO/UFES), do qual sou membro da equipe, e coletadas durante os anos de 2012/2013

3 Da revista "Fontes da Vida" (julho de 1962): Caxambu deveria grafar-se cachambu, porque vem de duas palavras africanas: cacha (tambor) e mumbu (música). O vocabulário servia, ao tempo dos escravos, para designar não só o instrumento que eles tocavam nas danças, mas ainda a própria dança ou batuque. Dizem uns que, outrora, os negros vindos de Baependy e circunvizinhanças costumavam reunir-se nas referidas Águas e aí celebravam batuques memoráveis, ao som dos seus caxambus e, assim, do hábito do convite "Vamos ao caxambu", ficou o termo aplicado ao próprio sítio da festa.

4 Tese de doutorado defendida em 2013 no Programa de Pós-Graduação Em Educação da Universidade Federal do Espírito Santo - neste trabalho proponho uma identificação de formas e ritmos diferenciados entre os jongos e caxambus do Espírito Santo. Esta questão é afirmada a partir das Oficinas de mobilização comunitárias do Projeto Jongos e Caxambus no Espírito Santo". práticas culturais que integram canto, dança, percussão de tambores, podem ainda adensar outros instrumentos como reco-reco e no Espírito Santo, a casaca. Sua procedência vem das antigas senzalas nas fazendas produtoras de cana-de-açúcar, depois de café da Região Sudeste, no século XVIII. Para Perez (2005), nessa época, o jongo e o caxambu eram expressões poéticas e, ao mesmo tempo, uma forma de comunicação baseada em "pontos" enigmáticos criados por negros bantu-angoleses que, assim, alimentavam uma complexa rede de resistência, bem como um espaço para exercitarem a sua sociabilidade em meio à situação de cativeiro.

Segundo o historiador, Robert Slenes (2007), "jongo" significa "a palavra que se atira como uma seta", arma poderosa que desafia os adversários, que codifica mensagens, como usavam os escravizados, tornando essa uma linguagem particular incompreensível para os senhores. Nesse sentido, Slenes aposta em algumas escritas conforme linguas africanas, encontradas em muitas etnias,

Eu acho que, eu apostaria que vem de Kikongo, 'nzongo', quimbundo. Acho que é 'songo' e umbundu, também 'songo' que é flexa ou bala. E, em kipongo, tem uma expressão 'nzongo myannua' que quer dizer a 'bala da boca'é, ou seja, a palavra dirigida, com uma, quer dizer, agressivamente. Em umbundo também tem uma expressão semelhante ou um provérbio que diz que a palavra é como uma bala (SLENES, 2007).

A definição de Slenes serve também ao Caxambu. No registro de práticas culturais do Estado do Espírito Santo, publicado pelo Instituto Nacional de Folclore, em 1982, o caxambu é descrito como dança em roda acompanhada de tambores, puíta e angoma - instrumentalização. Os cânticos, também chamados "pontos", cantados em verso, podem ser improvisados e 
cheios de simbolismo e enigmas. São classificados de acordo com o momento em que são cantados: "licença (no início da roda), de louvação, visaria, demanda, encante despedida”. Autores salientam que:

[...] no estado do Espírito Santo recebem ainda os nomes de 'Batuque', 'Jongo', Tambor ou Catambá, refletindo a origem angolana. Para eles, o Jongo expressa sua antiga função mágica, fetichista, num estilo nativo, onde mesclam-se elementos afro religiosos, atualmente amenizados por não existirem muitos jongueiros que conheciam os fundamentos e segredos da reunião (FUNARTE, 1982, p. 58-59).

A função mágica dos jongos, presentes em sua estética, são reverências aos ancestrais, aqueles que cantavam os jongos, que faziam e batiam os tambores em tempos de festas ou outros acontecimentos, mas também à toda negritude, interligando "Àfrica" aos seus descendentes. Mesmo que contrapondo uma África imaginada, a ancestralidade é algo que ultrapassa esse processo material, histórico, temporal.

As práticas culturais negras, produziram territorialidades cujo processos de identificação foram apropirados às tradições africanas ressignificadas no Brasil. Portanto, quando dialogamos sobre jongos e caxambus, nos referimos à forma como foram produzidas as danças, os pontos cantados, os tambores, mas também as formas como essas tradições circulam nas novas gerações, neste ponto, penso que poderemos tomar como ponto de reflexão a questão da ancestralidade, os processos de construção ancestral a partir dos cíclos representados nas rodas e a presença geradora feminina.

\section{Jongos, ancestralidades circularidades e a produção do feminino}

O conceito de ancestralidade remete aos ci- clos da vida. Esses ciclos são geracionais, vão para além do mundo animado, pois se constituem, salvo melhor tradução, como dogmas de fé, para além disso, como princípio fundante da vida, transcendentes. Sendo assim a questão intrínseca neste conceito, e em outros valores afro referenciados, remetem aos sagrados guardados por gerações e ao conhecimento dos detentores, portanto, remetem à um modo de ser e viver conservados nas práticas tradicionais afro religiosas.

Eduardo Oliveira, ${ }^{5}$ profundo estudioso da filosofia e cosmovisão africana, traz importantes reflexões sobre a questão da ancestralidade. Cita que uma das diferenças presentes no conceito comumente utilizado, está na forma como se pensa a ancestralidade ocidental, referenciada nos ancestrais familiares diretos, na descendência e uma outra perspectiva quando se trata da ancestralidade pela cosmovisão africana.

Em seu texto "Epistemologia da Ancestralidade”, Eduardo Oliveira (2011), concebe uma relação profunda para que possamos compreender os fundamentos da ancestralidade de maneira "simples", o que não é tão simples assim. Longe da reprodução de termos "mal-ouvidos", "mal ditos", "mal lidos" há que se ter cuidado sobre as reproduções que estereotipam a fala e a escrita, principalmente quando se trata do Sagrado Africano. Isso porque, qualquer coisa que remeta à religiosidade ou, como no caso, à ancestralidade africana, no Brasil e no mundo, é lida e entendida por visões racistas carregada de marcas. Sendo assim, a leveza dessa compreensão, fazse quando tentamos abrir um pouco mais nosso campo de visão "ocidental", para compreensão de outras formas de ser, viver, nesse sentido há necessidade de desconstrução dos nossos ra-

5 Professor Adjunto da FACED-UFBA e Presidente do Instituto de Pesquisa da Afro-descendência - IPAD. 
cismos cotidianos para que possamos compreender o princípio fundante da ancestralidade.

Ancestralidade é um princípio filosófico, consequentemente constitui-se em princípio social, já que pela cosmovisão africana não existem dualidades. Sobre este princípio, Eduardo Oliveira (2001;2003;2007) nos adverte que autores clássicos como Nina Rodrigues $(1984,1900,1982)$ Artur Ramos (1942;1943;1979) e Edison Carneiro $(1967 ; 1978 ; 1964 ; 1936)$ trouxeram o conceito para seus escritos, sem de fato, tê-lo aprofundado, até porque, não era comum neste tempo no Brasil, estudos sobre Filosofia Africana, portanto o termo se resumia aos estudos de candomblé, muito relacionado às linhagens de africanos, aos seus descendentes, uma relação com o parentesco consanguíneo.

A própria constituição do pensamento ocidental, encarregou-se de cisão entre práticas cristãs e não cristãs, até porque, o domínio das mesmas também instituía "poder" sobre territórios e os sujeitos que nele habitavam. Nesse sentido, os territórios carregam as heranças do colonialismo europeu, sob o paradoxo de em sua maioria terem produção fomentada pela dizimação dos povos originários e pelas diásporas africanas. Esse foi o desenho dos arredores urbanos e dos núcleos negros, pós-escravização. As práticas culturais, portanto, desde as senzalas, produziram outros contextos extraterritoriais, fortaleceram laços familiares, religiosos com o ambiente, em favor da vida, daqueles que se organizavam nesses núcleos constituindo novos laços familiares, para além dos laços consanguíneos, multiversais ${ }^{6}$. Os Jongos e Caxambus, já existiam nas senzalas, foram, portanto, cunhados nos princípios ancestrais. Ouvimos das mestras jongueiras histórias antigas de seus

60 termo refere-se ao Multiverso, contraponto para unicidade de Universo. pais, avós, contextualizando que existência das festas em torno das fogueiras eram momentos mágicos dos caxambus.

Eduardo Oliveira (2011) nos explica que a maioria das culturas africanas encerra sua sabedoria na forma narrativa dos mitos. "Talvez porque os mitos não segreguem as esferas do viver. Não se separa religião de política, ética de trabaIho, conhecimento de ação". Argumenta que essa relação talvez, se deva ao fato de que o mito conserve o mágico, e num "caso ou no outro, ele encanta, seja pela beleza explícita, seja pela beleza encoberta". Em todo o caso, não há dualidades, tudo é sempre tudo e nada ao mesmo tempo, é ser e não ser, processo, transformação e formação, afirma - a ética vem travestida de estética, seja na palavra, no vestuário, na música, na dança ou na arte. A vida é uma obra de arte e seus segredos são transmitidos através dos mitos que tem a função pedagógica da transmissão do conhecimento ao mesmo tempo em que se forma.

Conjugada à cosmovisão africana, ancestralidade compreende os princípios da vida, a construção histórico-cultural negra no Brasil. Constitui-se como um novo projeto sócio político fundamentado nos princípios da inclusão social, no respeito às diversidades, na convivência sustentável dos homens com o ambiente, no respeito às diferenças geracionais, à convivência com os mais velhos, à complementação dos gêneros, na resolução de conflitos, na vida comunitária. Nesse sentido, conjuga princípios educativos do viver, manifestando-se nos cotidianos das comunidades e consequentemente dando sentido às práticas culturais.

Sobre esse prisma, as práticas culturais jongueiras, compreendem essa relação ancestral, sob a qual os princípios da vida, dos fazeres cotidianos são valores transmitidos de geração em geração nas rodas. Consequentemente são traduzidos em diferentes perspectivas de ser 
estar no mundo. Por isso a relação do "feminino" como geradora, que impulsiona a vida é por vezes acolhida e incentivada nas práticas de jongos. Neste mesmo princípio a construção social da mulher, transcende o gênero, porque qualifica sua composição sócio-política de enfrentamento às adversidades raciais. É por meio da compreensão ancestral que os jongueiros territorializam o feminino, porque cabe às Mestras direcionarem seus grupos, e exercerem liderança. São as Mestras Jongueiras que tomam as decisões sobre as organizações dos grupos. Muito embora o viés masculino seja indistintamente forte, ainda se conjuguem sobre o prisma do patriarcado (hooks, 2019) e domínio dos corpos, tem-se a autorreferencia feminina, sem a qual jongos e caxambus não teriam a mesma força.

\section{Interseccionalidades das mulheres jongueiras}

Dentre as muitas dimensões que possibilitam discutirmos a corporeidade presente nas práticas culturais estão as interseciconalidades das mulheres negras. Importante justificar que a apropriação autorreferenciada, delimita as práticas culturais pelo processo de reconhecimento sobre as especificidades das mulheres do jongo.

Sobre estas especificidaes, destacamos as violências sofridas no período de escravização demarcando feridas nos corpos negros, em especial nos corpos das mulheres, que de forma individual ou coletiva, expressavam em seus prórpios corpos o rejeito ao regime de opressão, construindo cotidianamente resistência (SCOTT,1989). De certa forma, o trabalho da mulher escravizada e pós escravização, tanto no campo, quanto na cidade foram constituídos de práticas aquilombadoras, políticas, culturais, religiosas, que até hoje são reconhecidas nos terreiros das zeladoras de santo, "Mães" Matriarcas, nas lutas políticas das ancestrais. Mulheres como Aquatune, Dandara, Constância de Angola, Zazimba Gaba, Lélia Gonzalez, Sueli Carneiro, Luiza Bairros, Mestre Nêga (Jongueira Sapê do Norte), Mestre Gessy (Jongueira Sapê do Norte), Mestre Maria Amélia (Jongueira Sapê do Norte), são mulheres que incorporaram em seu "DNA", essas lutas e de alguma forma se autorreferenciam em suas estratégias de enfrentamento. Nessas lutas, a resistência agregadora, transforma o coletivo, principlamente por se constituir em um espaço a mais para companheirismo e solidaridades estimuladas nos convívios e partilhas cotidianas.

De fato, as conquistas e historicamente as lideranças, foram feitos quase escondidos, pois o patriarcado dominante (hooks,1989) as excluia dos espaços de decisão. Assim, quando falamos de resistência e liderança nos jongos, trazemos esse exercío de tomada de decisão nos coletivos.

O conceito de intersseccionalidade discutido por Kimberle Crenshaw (1989), Carla Akotirene (2019), Patrícia Collins (2019-2020) refere-se aos processos intercalados de compreender os ofícios assumidos por mulheres considerando seus múltiplos espaços de inserção e o enfrentamento às opressões cruzadas, raça, classe, gênero, sexualidade (acrescentaria religiosidades). Sistemas semelhantes de poder são interdependentes e mutuamente constituídos. Portanto quando se trata de pensarmos resistências e enfrentamento de mulheres negras a esses encadeados opressivos, estamos cruzando referenciais que interligam todo processo sobre esta construção social do feminino, distintas entre os aquilombados. ${ }^{\text {? }}$

\footnotetext{
7 Imprimimos um outro sentido para os aquilombamentos, que de acordo com o (ADCT 68 - CF/88) Designa remanescentes de quilombo a partir do conceito reelaborado garantido no artigo 68 do Ato das Disposições Constitucionais Transitórias (ADCT - CF/ 88), como locais de resistência,
} 
A região de Sapê do Norte $^{8}$ - compreende São Mateus e Conceição da Barra, é relativamente um território de aquilombamentos. As comunidades negras que habitaram no passado, foram trazidas ainda escravizadas para região. Muitos serviram às fazendas produtoras de farinha, e outros reuniram-se nas comunidades independentes - aquilombados, sobrevivendo da agricultura de subsistência e do comércio local interno, como ainda ouvimos nos dias de hoje da "fé em Deus".

Quando o assunto é devoção, a fé transcende e complementa o processo de organização comunitária. As devoções à São Benedito (São Mateus - comandado por Mestre Nêga), São Bartholomeu (Quilombo Novo - comandado por D. Carmen, Kelly Nay), Santa Bárbara (LinharinhoMestra Gessy Cassiano), Sant’ Anna (Santana - Comandado por Mestre Maria Amélia), são santos cujas devoções guardadas pelas Mestras Jongueiras, perduram atravessando as adversidades temporais.

Comandar um jongo é muito mais que apenas estar à frente nas "representações" como dizem os próprios jongueiros. Implica assumir responsabilidades dos ensaios, das reuniões para organizarem as devoções, correspondências com os festeiros, adornos das procissões, organização das roupas e instrumentos, e todas necessidades advindas dos trabalhos com o grupo. Ainda incluem zelar pelos participantes, com colaborações inclusive entendendo-os como parte do

acolhimento, produção histórica e cultural. 80 'Sapê do Norte' era o longínquo, ao longo dos vales dos rios Cricaré e Itaúnas, região há muito habitada por agrupamentos negros e camponeses que assim se organizaram e se apropriaram desta natureza desde os tempos da escravização colonial até meados do século XX. Dona Maria Caetano, 69, relembra que seus avós maternos eram do 'tempo dos barões' e viviam numa localidade próxima à sede da antiga fazenda escravista da Cachoeira do Cravo, de propriedade do Barão dos Aimorés. (Ferreira,2009) processo familiar. As representações políticas também ficam a encargo dos mestres. São representantes em conselhos de culturas, assossiações de bairro, colaboram na própria estrutura comunitária. São zeladores das famílias jongueiras porque reúnem laços sociais que se fortalecem nas convivências cotidianas. São essas responsabilidades, atreladas às realidades de enfrentamento ao patriarcado, às questões políticas, religiosas, que alavancam as lideranças femininas.

As mestras jongueiras são levadas a "cuidar" dos interesses dos grupos nas representações onde se fizerem necessárias, inclusive porque a comunidade jongueira colabora nas tomadas de decisões em apoio a mestra. Logicamente existem discensos e muitas dificuldades para comporem esse processo, mas de certa forma, gestar o trabalho comunitário apresenta-se como um desafio aprendente das relações políticas tão necessárias na consolidação dos espaços de poder da mulher.

Reflexões históricas publicadas por Aguiar (2005-2007) trazem registros de alguns "Mestres Brincantes” entre elas o de Mestre Nega, Dilzete Nascimento, que assumiu o grupo de Jongo de São Benedito, pós Mestre Geraldino dos Santos e Mestre Salvino9. O Jongo de São Benedito, conduzido por Nêga, é um dos mais representativos da região. Coube a ela dar continuidade nos ensaios, organização das festas, devoção, revisão dos cantos juntamente com D. Edézia, irmã de seu Salvino. A voz de Nêga ecoa nos processos de construção e afirmação dos jongueiros, por ela, o repeito à história e aos integrantes vem em primeiro lugar,

Nêga - E aonde apresentar o grupo? Como também, né? A roupa era comum, descalço, dois reco-reco, dois tambores e... na porta da igreja de São Benedito. Quem mais prejudi-

9 ANDRADE, Tese de Doutorado, UFES. 
cava, quem mais proibia, as pessoa que mais provocava, mais incomodava, que o grupo incomodava? O próprio pessoal da religião católica, tá? A própria igreja foi quem mais incomodô, a igreja sempre bateu porta nas nossas caras. Os... corais iam cantá na igreja depois da missa. Eles ficavam cantando horas mais horas, pra que nóis num pudesse fazê nossa apresentação, e nóis ali esperando. De braço cruzado. Hoje ninguém faz mais isso, né? Nóis ali, esperando de braço cruzado, quando bem o coral quisesse terminá lá. Aí a gente ia cantá o nosso [expediente] ali, batê nosso tambô pra ir embora pra casa. Cansamos de fazê isso. Hoje igreja nenhuma bate porta na nossa cara. Hoje, se batê, a gente manda abri. Com certeza, entendeu? A gente fez uma grande amizade com os padres, com os leigos, né? Nas comunidades. Então não tem mais isso! [...] (Mestre Nega - Oficina Santana, ago. 2012).

O relato de Mestre Nêga, apresenta a importãncia de sua liderança denunciativa frente $\mathrm{O}$ grupo, a superação das dificuldades e as conquistas alcançadas durante sua gestão. A ênfase desta narrativa está justamente no percurso histórico de discriminação das práticas culturais, da não valorização, do desrespeito e sobretudo na ressignificação das lutas empreeendidas em favor do reconhecimento das tradições afro-brasileiras no Sapê do Norte. Esse desabafo foi muito comum entre os grupos durante as Oficinas de Mobilização Comunitária. Comumente ongueiros explicavam que em tempos passados muitos não tinham vestimentas adequadas, transporte para as apresentações, e ainda tinham dificuldades em se comunicarem em suas próprias comunidades. Muitas dessas dificuldades ainda persistem em tempos atuais.

Mestre Nêga é uma mulher negra quilombola. Descende dos aquilombados organizados nas matas do córrego do Aterro na Região do Sapê. Sua liderança foi se construindo sobre muitos enfrentamentos e discriminações sofridas na região. O grupo de Jongo de "São Benedito", se constituiu em mais um aporte para empreender lutas junto da comunidade. Nêga foi escolhida por Mestre Salvino Rodrigues Pereira para a direção do grupo de jongo, porque, segundo Aguiar,

[...] Nêga éa personificação das valentes mulheres quilombolas do Vale do Cricaré, que enfrentaram não apenas os temidos capitãesdo-mato, mas até hoje enfrentam todos os tipos de discriminação e preconceito para manter viva uma tradição de relevante papel na difusão da cultura popular [...] (AGUIAR, 2007, p. 22).

Percorrendo o caminho das devoções e procissões, São Benedito é louvado em todo o norte pelos grupos de jongo, mas também não se perdem as devoções à São Sebastião, Santas Almas, Santa Bárbara, Santo Antônio e aos Pretos Velhos.

O povoado de Santana localiza-se no município de Conceição da Barra. Foi nessa região onde se estabeleceu a fazenda de Dona Rita da Conceição da Cunha, que segundo relato do escritor e jornalista Maciel de Aguiar, possuía uma sesmaria de terras que compreendia a grande área dos dois municípios, mais precisamente da margem norte do Rio Cricaré até o córrego São Domingos.

Em visita à comunidade de Santana, ouvimos que antigamente havia bailes em homenagem a São Bartho (São Bartholomeu). Esses bailes, que eram predominantemente marcados por mulheres, foram crescendo e se transformando no que hoje encontramos como procissão realizada na Igreja de São Bartholomeu. Dona Maria Amélia é uma fiel representante desses bailes, era ainda menina quando se deu conta da devoção a São Bartho, repassadas por sua mãe e avós. Ele relembra que o jongo sempre acompanhou as devoções, 
Maria Amélia: É o povo do mato que trouxe São Bartho. Só não sei explicar, porque foi a minha bisavó. Foi a minha bisa que conseguiu, aí no dia em que eles foram libertados era meia-noite, aí da meia-noite até o meio-dia do outro dia eles fizeram Jongo, aí deu continuidade.

O povo do mato a que se refere, são os aquilombados, provavelmente "parentes" mais distantes, no entanto, com o passar do tempo as traduções (BHABHA, 2010 a.) ressignificam as devoções. Os seja, ainda hoje10, as mulheres jongueiras acompanham a procissão com São Bartho aos braços, mesmo com um quantitativo menor de senhoras, porque muitas já não aguentam mais fazer o cortejo pelas ruas do bairro, mas buscam se fortalecer na crença e na presteza divina de auxílio do santo na hora do parto ou de suas dificuldades,

$\mathrm{M}^{\mathrm{a}}$ Amélia: É devoto das mulheres. É por isso que quando era baile era só de mulhere passô pro jongo só mulher. Tem homem, mais é no reco-reco, nos tambô. Tá entendendo? É assim. Mais é antigo, oh!

Sobre antiguidade da devoção, D. Roxa explica que recebeu de sua família (mãe e avós) a guarda de São Bartholomeu. D. Roxa, senhora oxagenária da comunidade de Santana tem sob sua guarda um baú de recordações. São roupinhas dadas em promessas pelos partos bemsucedidos à São Bartholomeu. Ela nos contou que recebeu o santo como herança de família, foi parteira e guardiã de São Bartholomeu por mais de 30 anos. Disse que há muitos anos atrás

10 Esperamos que pós pandemia de Covid 19, as procissões possam novamente acontecer. Neste momento exatamente estamos em isolamento social, o que impede realização de atividades de aglomeração de pessoas. No entanto, para escrita deste texto, tomamos como base os acontecimentos até 2019, quando ainda não se tinha noção de tamanho perigo para humanidade. eram muitas as adversidades do campo, na época, não havia muitos médicos na região e as mulheres aprendiam com as mais velhas os ofícios de parteiras. Somente muito mais tarde receberem treinamento especial de especialistas da saúde para o ofício. Assim, os partos eram realizados com a imagem do santo e de Nossa Senhora. As mulheres grávidas faziam frequentemente promessas ao santo para que o parto desse certo,

Mestre Maria Amélia [...] Porque São Berto ele era dos escravos, ele era da minha bisavó. Então nós não podemos duvidar do que eles fazem, porque naquela época em que ele foi parteiro não existia médico pra fazer parto das mulheres. E nunca'... Só a minha tia (parteira), ela pegou o parto de duzentos e cinquenta crianças. Ainda tem, se tiver alguma lá hoje eu vou apontar pra vocês, que foi ganhado em neném junto com ele [...]

Como guardiã e por estar com idade avançada, D. Roxa sentiu-se na obrigação de continuar a devoção passando a guarda de São Bartholomeu para Maria Amélia, sua sobrinha.

Maria Amélia: Eles vem sim. Eu sei que eles vem sim. Então, a gente fica naquela recordação. Naquela lembrança do que a gente já foi. Do que a gente viveu. Porque é muito, só quem já viveu umas tradições destas que... Não tem como esquecer. Então, quando chega essas datas assim... E no dia de Santa Rosa de Lima me dá a sensação da minha mãe. Eles festejavam o São Bartolomeu no dia vinte quatro e no dia trinta a minha mãe festejava Santa Rosa de Lima. Era ladainha e o Jongo, tudo junto.[18min.13seg.]

O jongo de São Bartholomeu foi refundado por D. Tininha, que se tornou mestra, também em promessa. Ela reviveu o jongo após muito tempo adormecido, na intenção de continuar a brincadeira entre as mulheres da região. No 
entanto, seu desejo era que a neta Kelly Nay pudesse quando crescida assumir a liderança. Para isso, seu filho Tatu deveria organizar-se e guardar o jongo até a neta ter condições de assumi-lo. Por se tratar de um jongo de mulheres, Tatu, filho de D. Tininha, assumiu por um tempo, porém muitos motivos levaram-no a desistir da liderança, entre eles o que comumente alegava - "Jongo de São Bartholomeu é um jongo de muIheres - Essa é a devoção do santo", assim passou para sua prima Carmem, para que pudesse asssumir a responsabilidade do comando do jongo até Kelly Nay sentir-se preparada para tal. Kelly Nay, encontra-se atualmente com 24 anos, oscilando em assumir a responsabilidades das atividades de São Bartholomeu.

Com o tempo, é possível perceber que as devoções vão se ressignificando, ao mesmo tempo que alguns grupos atravessam fases entre sua organização e reorganização, outros grupos acentuam-se caminhando e fortalecendo-se. É o caso do grupo de Jongo de Santa Bárbara, de Linharinho, comandado, por Mestre Gessy.

Mestre Gessy se autoidentifica como, lavradora da região, mulher negra quilombola, Alabê de Santa Bárbara. Seu maior desejo era reafirmar o jongo de Santa Bárbara, que para ela tinha um caráter fundamental de devoção à santa. Esse jongo se reorganizou durante o Projetos Jongos e Caxambus no Espírito Santo, e renasceu totalmente feminino.

O jongo de Santa Bárbara, tem seus fundamentos relativos à $\mathrm{D}$. Oscarina Cosme, respeitada líder religiosa da região - "Mãe Oscarina" - Mãe oscarina, além de mãe de muitos jongueiros, também conduzia as mesas de Santa Bárbara e Santa Maria. Foi ela quem nos deu inicialmente algumas pistas dos jongos que aconteciam nos intervalos dos trabalhos da Mesa de
Santa Bárbara e da Mesa de Santa Maria. ${ }^{11}$ D. Oscarina - no período do projeto ainda viva - conversou muito sobre suas memórias, e nos disse que entre uma sessão e outra da mesa de Santa Bárbara, havia rodas de jongo.

Observamos que a condição das disputas territoriais, políticas internas trouxeram sérios danos às comunidades de Conceição da Barra, ainda mais para a Comunidade de Linharinho. Suas lideranças, forjadas na luta quilombola, constituíram deste território do Sapê o sentido de resistência, da luta pela terra. Conservaram as lideranças femininas voltadas para o sagrado religioso, por compreeenderem os fundamentos da ancestralidade. Das formações e devoções a Santa Bárbara, emanaram possibilidades de reformulação dos jongos, porém, desvinculados da questão religiosa, porém, guardados os princípios de liderança, da circularidade e dos processos ancestrais. Diante das novas perspectivas de organização dos grupos, o jongo de Santa Bárbara, passou a contar com o comando de Mestra Gessy, as meninas do entorno, sem, contudo, participarem das mesas. Gessy tonrou-se mestra a partir da retomada dos jongos, durante a realização do projeto jongos. Com uma roupagem exclusivamente feminina, a nova mestra, retoma os passos que antes à conduziram a essa importante devoção à mesa de "Santa Bárbara”.

Em Linharinho, os encontros para ensaios do Jongo de "Santa Bárbara", tambem são encontros de conversas, brincadeiras e alegrias. Mestra Gessy, aproveita para conversar, passar alguns ensinamentos dos antigos, trazer algumas palestras, algo a mais que ela entende como necessidade para moças da região. Mestra Gessy continuou sua caminhada, levando soli-

11 Religiões de Matriz Africana com práticas no norte do Espírito Santo. 
dariedade, construindo outras possibilidades e atualmente aguarda finalização da pandemia de Covid para empreender novos projetos com as mulheres do Sapê.

\section{Concluindo...}

Historicamente o corpo das mulheres negras foi desvalorizado, uma combinação de subalternidade, dor, silencio, muitas vezes usado como sinal de erotização ou de exclusão, perpetuando-se no presente desde a casa grande e a senzala.

Desenvolver o protagonismo feminino como lideranças, foi uma das formas encontradas pelas comunidades negras para ruptura desses racismos de marca histórica do corpo feminino.

As políticas do corpo são formas construídas pelas comunidades negras para compreensão de suas ancestralidades, mas também de fazerem mulheres negras se autorrefereciarem, por meio das narrativas de empoderamento, de memórias, construindo consciência positiva sobre seus corpos e suas histórias.

De uma outra perspectiva, nos ensinam a identificarmos as funções políticas das estéticas africanas contra os padrões ocidentais dominantes e até mesmo de enfrentamento ao patriarcado, que destituiu o corpo feminino dos espaços de poder. Portanto as práticas jongueiras também são formas de pensarmos a descolonização dos corpos, das mentes, desracializar no complexo sentido de religação ancestral.

Ser uma Mestra Jongueira, institui percursos de empoderamento, liderança associados a independência, autorreferência, pertinentes aos processos de identificação das práticas culturais de comunidades negras brasileiras na diáspora.

\section{Referências}

AGUIAR, Maciel de. A divindade de São Benedito: o santo dos humildes e dosoprimidos. Revista Vitória, ano 1, n. 9, p. 46-53, jun. 1982.

AGUIAR, Maciel de. $O$ mestre de jongo de São Benedito. In. AGUIAR, Maciel de.

Brincantes e quilombolas. São Mateus: Memorial, 2005.

AKOTIRENE, Carla. Interseccionalidade. São Paulo: Pólen, 2019.

ANDRADE, Patrícia Gomes Rufino. A educação do negro na comunidade de Monte Alegre/ES em suas práticas de desinvibilização da cultura popular negra. 2007. Dissertação (Mestrado em Educação) - Programa de PósGraduaçãoem Educação, Universidade Federal do Espírito Santo, Vitória, 2007.

ANDRADE, Patrícia Gomes Rufino. Entre Jongos e Caxambus: Processos Educativos nas práticas religiosas afro-brasileiras. Tese - Programa de Pós-Graduação em Educação, Universidade Federal do Espírito Santo, 2013.

BASTIDE, Roger. As Américas Negras: as civilizações africanas no Novo Mundo. São Paulo: Difusão Européia do Livro; EDUSP, 1974.

BHABHA, Homi. In the Case of Making: Thougths on Third Space. In (Org) IKAS, Karen; WAGNER, Gehrard. Communicating in the Third, Space. New York: Routledge, 2009. . Introdução. In BHABHA, Homi. O Local

da Cultura. Belo Horizonte: UFMG, 2010 a.

COLLINS, Patrícia Hill. Pensamento Feminista Negro. Tradução de Jamille Pinheiro Dias. Boitempo, São Paulo, 2019.

COLLINS, Patrícia Hill. Learning from the outsider within: The sociological significance of Black feminist thought. Social problems, v. 33, n. 6, p.14-32, 1986.

CRENSHAW, Kimberle. Demarginalizing the intersection of race and sex: A black feminist critique of antidiscrimination doctrine, feminist 
theory and antiracist politics. The University of Chicago Legal Forum, p.139-167, 1989.

GUIMARÃES. Aissa Afonso. Caxambu Alegria

de Viver": memória e patrimônio afro-brasileiro em Vargem Alegre (Cachoeiro de Itapemirim ES). Trabalho apresentado na $29^{a}$ Reunião Brasileira de Antropologia. agosto de 2014, Natal/RN.

KILOMBA, G. Memórias da plantação: episódios de racismo cotidiano. Rio de Janeiro: Cobogó, 2020.

HAESBAERT, Rogério. Território e Multiterritorialidade: Um Debate. GEOgraphia, v. 9, n. 17, p.19- 45, 2007.

HOOKS, bell. E eu não sou uma mulher? MuIheres Negras e o Feminismo. Rosa dos tempos. Rio de Janeiro. 2020.

HOOKS, bell. Choosing the margin as a space of radical openness. Framework: The Journal of Cinema and Media, v. 36, p.15-23, 1989.

OLIVEIRA, Eduardo David de. Filosofia da Ancestralidade: Corpo e Mito na Filosofia da Educação Brasileira. Curitiba: Editora Gráfica Popular, 2007 a.

. Ancestralidade na Encruzilhada. Curitiba: editora gráfica Popular, 2007 a.

PEREZ, Carolina dos Santos Bezerra. Juventude, música e ancestralidade nojongo: som e sentidos no processo identitário. 2005. Dissertação (Mestrado em Educação) - Programa de Pós-Graduação em Educação, Universidade de São Paulo, São Paulo, 2005.

RODRIGUES, Nina. As Raças Humanas e a Responsabilidade Penal no Brasil. Bahia. 1984.

SCOTT, J. C. Everyday forms of resistance. The Copenhagen journal of Asian studies, v. 4, p.3333, 1989 .

\section{Patrícia Gomes Rufino Andrade}

Doutora em Educação - Diversidade e Práticas Inclusivas (UFES). Professor Adjunto do Departamento de Educação, Política e Sociedade (DEPS). Graduado em Geografia (UFES), Pedagoga. Pesquisadora do Núcleo de Estudos Afro-Brasileiros da UFES. Pesquisa Geografias e territorialidades: Políticas Educacionais para Populações Afro-Brasileiras: Quilombolas, Territorialidades afro-religiosas; Educação do Campo, Práticas Pedagógicas para Educação Étnico-racial, Territórios periféricos. PhD em Economia e Politicas Institucionais - Universidade de Minnesota-USA. Professora do Mestrado Profissional em Educação (PPGMPE/UFES) e colaboradora do Programa de Pós-Graduação em Comunicação/ Pós-Com/UFES. 